\title{
Modeling Processes of 4th-Year Middle-School Students and the Difficulties Encountered ${ }^{*}$
}

\author{
Ali Eraslan ${ }^{a}$ \\ Ondokuz Mayıs University
}

Sinem Kant ${ }^{b}$

Ministry of National Education

\begin{abstract}
Mathematics teachers have recently begun to stress the need for teaching models and modeling approaches that encompass cognitive and meta-cognitive thought processes for every level of schooling, starting from primary school through to higher education. The objective of this study is to examine modeling processes with the help of modeling activities for 4th-year middle-school students and to determine the difficulties encountered in the processes. The study was conducted with 4 th-year students from a lower socioeconomic status who were enrolled in a public middle school. A preliminary study was carried out. Later, three students were chosen as a focus group to work on a model-eliciting activity called the Volleyball Problem, and the entire process was recorded on video. The mathematical thoughts that the students developed during the modeling process and their written responses were then qualitatively analyzed. The results obtained showed that the students were able to produce many new and different ideas. They were able to discuss various assumptions before reaching a conclusion and the activities helped them to think deeper and develop their mathematical thinking. At the same time, however, it was found that the students experienced certain difficulties during the model-eliciting process in terms of understanding, developing, and constructing an adequate model.
\end{abstract}

Keywords: Middle-school students $\bullet$ Model-eliciting activities $\bullet$ Mathematical modeling $\bullet$ Difficulties or challenges

* This study was presented at the 10th National Science and Mathematics Education Congress held on June 27-30, 2012.

a Assoc. Prof. Ali Eraslan (PhD), Mathematics Education Department, Faculty of Education, Ondokuz Mayıs University, Kurupelit, Samsun 55200 Turkey

Research areas: Models and modeling; Visualization; Teacher education

Email: aeraslandomu.edu.tr

b Sinem Kant, Ministry of National Education, Korgan Regional Elementary Boarding School, Korgan, Ordu 52700 Turkey

Email: sinemkontahotmail.com 
In recent years, one of the basic concerns that have led mathematics teachers to work on approaches to models and modeling has been the inadequacy of traditional problem-solving activities in teaching students how to develop their problem-solving skills (Greer, 1997; Mousoulides, Christou, \& Sriraman, 2006; Schoenfeld, 1992 as cited in Kertil, 2008). The importance of this lies in the fact that one of the most prominent goals of education today is to train individuals who are capable of analytical thinking and have the capacity to generate effective and creative solutions for problems (Kilpatrick, 1992). Educators in different fields emphasize that success after school depends upon new understanding and skills. These skills include the abilities of structuring, defining, clarifying, manipulating, and projecting within complex systems (English, 2002). It is these skills that play an important role in achieving success, planning multidimensional and multifaceted projects, and controlling and developing communications (Gainsburg, 2006). In addition, these skills contribute greatly to interpreting and mentally analyzing conceptual structures (English, 2002; Gainsburg, 2006; Lesh \& Doerr, 2003). The approach that will enable students to develop such skills as engaging model-eliciting activities that lead to mathematical modeling (English \& Watters, 2005; Lesh \& Doerr, 2003).

In its most general sense, mathematical modeling is the mathematical expression of real life experience. This is, however, more than taking a situation from the real world and interpreting it based on simple formulations using appropriate variables. Modeling encompasses the processes of observing the situation, identifying the relationships involved, applying mathematical analysis, developing model,s and revisiting the interpretations of these (Swetz \& Hartzler, 1991). It was the applicability of mathematics to real life situations, the facility with which mathematical knowledge lends itself to concrete application, and the way mathematics can be used to produce more analytical and practical solutions that led to the birth of the idea that mathematical modeling should be taught in primary and middle schools (Mousoulides et al., 2006).

Studies conducted in primary schools have shown that modeling activities provide students with: (a) a powerful tool to use in developing critical and high-level thinking skills (English \& Watters, 2005), (b) a new and effective learning environment where existing deficiencies in conceptual knowledge are identified and new mathematical knowledge is gained (Chamberlin, 2004), (c) encouragement to use different and various representations to explain conceptual systems (Boaler, 2001; English \& Watters, 2004; Mousoulides, 2007), and (d) increased communication skills by encouraging students to share their own mathematical notions and understanding (English, 2006). On the other hand, it has also been noted that students feel challenged at various stages of the modeling process, particularly in understanding the problem, structuring and simplifying the problem, making use of variables, discovering the relationships between variables, developing appropriate assumptions, verifying the relationship between real life and the model, and validating the model (Blum \& Leib, 2007; Crouch \& Haines, 2007; Maaß, 2007; Sol, Gimenez, \& Rosich, 2011). It has been asserted that the process has an impact on how students think mathematically, their approach on and experience with modeling activities, their own life experiences, and their attitudes toward mathematics (Ferri, 2011; Schoenfeld, 1992). Model-eliciting activities provided in the literature as an alternative to traditional problem-solving activities have been shown to be an effective tool in developing the skills of students for applying mathematics to different fields. It is therefore because of this that the objective of this study is to use model-eliciting activities that would give students the opportunity to create and develop their own mathematical ideas and processes for the purposes of examining 4th-year middle-school students as they conduct their modeling processes and identifying the difficulties they face, if any.

\section{Theoretical Framework}

Stillman, Galbraith, Brown, and Edwards (2007) developed a modeling cycle to identify the student modeling process and the difficulties they encounter as they go through the various stages of this process (Figure 1). In this cycle, individuals are in constant transition between real life and mathematics during the modeling process. The process in fact starts with a messy, real-world situation. A problem emerges out of this situation and the model is reached through the use of mathematics. Later, a solution emerges out of the various mathematical processes that are applied to the model. Ultimately, the solution obtained is first interpreted and then proved to be correct and valid. If the solution or the process chosen does not fit the real life situation, the steps are revisited and reviewed once again, or the entire modeling process is repeated. 


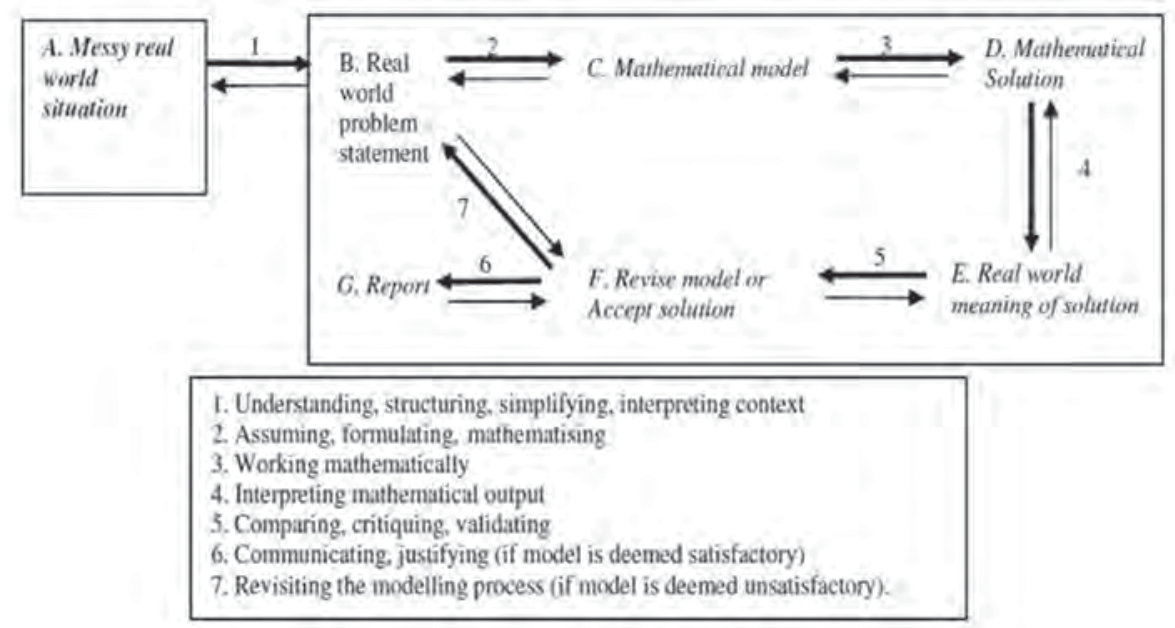

Figure 1: Stillman et al's (2007) modeling cycle.

Stillman et al. (2007) explained the cognitive thought processes involved in making the transition from one stage of modeling to the next: (1) In making the transition from the messy, real-world situation to expressing the real-world problem, one explains the general status of the problem, makes simplified assumptions, and establishes strategies; (2) In making the transition from the real-world problem to the mathematical model, one identifies the dependent and independent variables contained in the algebraic model, represents the elements mathematically with applicable formulas, formulates relevant assumptions, and selects the appropriate strategy that will automatically support the formula in multiple situations; (3) In making the transition from the mathematical model to the mathematical solution, one applies the appropriate symbolic formula, uses mathematical tables for calculation, and obtains generalized solutions that will allow an interpretation of the results; (4) In making the transition from the mathematical solution to the real-world meaning of the solution, one identifies the counterpart of the mathematical results in the real world, integrates the arguments to validate the interpretations, and expands previous limitations with a new interpretation to produce a conclusion, and (5) In making the transition from its meaning in the real world and revisiting the model to revise it, or in making the transition to the acceptance of the solution, one reconciles unforeseen results with real life, reviews the possible effects of the mathematical results in real life, reconciles the mathematical and real-life aspects of the problem, and reviews the model's detailed results in the light of their adequacy in the real world.

\section{Method}

This is a qualitative study that was conducted using modeling activities to examine the modeling processes among 4th-year middle-school students and to identify the challenges faced in this process, if any, along with the reasons for their difficulties. This research is a case-study design, using a single group as well as in-depth review and analysis. A case study is the examination and analysis of one or more situations as a whole within its own boundaries (Creswell, 1998). The situation in this study is a case study on a focus group of 4 th-year middle-school students with an examination made on their modeling processes. The aim of a focus group study is to allow for certain subjects that may not come up in individual talks to be brought up by other individuals in the group so that additional interpretations may emerge. In this way, the dynamics of the group have a significant impact on the scope and depth of answers given to questions.

\section{Participants}

This research was conducted during the 2011-2012 academic year, in a middle school in a large city along the Black Sea Region of Turkey with students of families from lower socioeconomic backgrounds. The students in one of the 4th-year classes of the middle school, where the researcher was a teacher, were assigned a modeling activity to work on for two class-hours every week for six weeks as a group. The process included the discussion of the concepts of models, modeling, mathematical modeling and model-eliciting activities. After the basic concepts 
of the subject of modeling were taught and enough time was allotted for the students to gain experience with this skill, a group of three students, two boys and a girl, were selected to form a focus group. The criterion sampling technique was used as a form of purposeful sampling employed in the formation of groups, meaning that the students were chosen in terms of criteria that had previously been determined. Besides ensuring that the students chosen were those who had successfully carried out the modeling activities, care was also taken to see to it that the students in the group had worked with each before, were assertive and self-confident, and able to easily express themselves.

\section{Data Collection Tools}

After a six-week preliminary study, the focus group gathered together in the classroom and was given the modeling activity of working on the volleyball problem. The volleyball problem is a modeling activity in which there are many ways of solving the problem using the data offered, with a variety of different possible results (Lesh, Hoover, Hole, Kelly, \& Post, 2000). Modeling activities can be defined as working with problematic situations using different possible solutions that reflect non-routine and complex life-situations where individuals are asked to interpret the situation mathematically and help each other in their decision-making to describe and formulate the process or method mathematically (Lesh \& Zawojewski, 2007; Mousoulides, 2007;). In these types of activities, students know only the criteria they are expected to find, but they do not know the nature of the result from their developmental or search efforts. That is, they do not know what they will be confronted with at the end of the activity (Lesh et al., 2000). In the process, the students are asked to use the five variable characteristics that affect a player's volleyball-playing potential, (a) height, (b) vertical-leaping ability, (c) speed in running a 40-meter dash, (d) successful serves, and (e) spike results, in order to evaluate and correlate the formation of a model. The model created should divide the eighteen female players in the problem into three teams of equal strength and also be valid, applicable, and generalizable enough to be used in the future for selecting teams from players that will participate in a volleyball camp. The total of 55 minutes allotted to the focus group's work was first recorded on video. Next, the problem was solved and the students analyzed their solutions qualitatively, examining the written documents they used during the problem solving. Before the discussions, the students were given information on the study, informed that their real names would be kept confidential, and that the research would involve the development and construction of a model. It was explained and stressed that modeling was a new perspective in mathematics teaching, that the model developed would be based on their views and the ways they solved the problem, and therefore their performance was important for the research.

\section{Data Analysis}

The mathematical thoughts and written responses of the 4th-year middle-school students in the focus-group activity on the methods of solving the volleyball problem were analyzed in the light of the modeling cycle developed by Stillman et al. (2007). In this process, the models developed by the students, every kind of representation and visual related to these, the processes used, the relationships formed, the rules that were made up, and the patterns that formed were considered (Miles \& Huberman, 1994). In addition, to increase the study's internal reliability (internal consistency), the modeling processes as well as the interpretations were offered through direct quotes and reviewed not only by the highly experienced researcher but also separately by two colleagues with degrees in education from the same university who had experience in qualitative research. Ultimately, full agreement was reached on the modeling process. To increase the transferability of the research, the research process and the design, participants, data collection instrument, data collection process, data analysis, and interpretation are described in detail.

\section{Findings}

The modeling processes of the focus group students in their attempt to create a model by revealing and writing down their mathematical thoughts are described below. The male students in the group have been assigned the aliases Ali and Onur, and the female student has been given the name Sude.

\section{Modeling Processes}

The students first compared the components of the variable of height, and by using the grouping system developed by all the students, attempted to divide the group members into three equal teams. The data belonging to the variable of height was 
first analyzed, starting with the highest value. The process of distributing the players into the groups from the tallest player down to the shortest was carried out, accompanied by the following discussion between the students:

Ali: Look, (pointing to Bahar) she is tall!

Onur: 1.85 meters.

Sude: There's someone who's 1.78 here. Let's put her in the second group then.

Ali: Let's take these two (pointing to Elif and Neslihan).

Onur: There's a 1.73 who's shorter than 1.78.

Ali: Let's draw a circle around this one.

Sude: There's a 1.75 .

Ali: There's a 1.73 .

Onur: There's a 1.73. There's a 1.75 .

Sude: $1.75,1.75$; there are two 1.75 's.

Ali: Write down 1.75. Sude, you write it.

Onur: For the 1st group?

Sude: There are two 1.75 's.

Onur: For group 1?

Ali: Yes. Sude, you write it. Write down Duygu for 2. And let's write down 1.73 for the third one.

What else shall we write?

Onur: Let's put down ... for 1.73. Nalan.

Sude: 1.73 , two, Nihan and...
Ali: Write down Nihan. Write down Nalan. It doesn't matter.

Sude: Write down one of the two, in other words... (Nalan is written into the 3rd group)

In the excerpt above, the students distributed the players randomly into three groups without putting them in order, according to the variable height. During this distribution, three of the players, Deniz (1.78), Nihan (1.73) and Seda (1.55) were left for last. When Onur pointed to the third group and objected by saying, "Look, the short ones are here," the arrangement of the players was discussed once again and groups were reformed (Figure 1.1):

Sude: Let's put one in each, then.

Onur: We'll put one in each.

Ali: Three of them are 1.78, so because there will always be less here let's write up Deniz for...

Sude: The 3rd group.

Ali: Yes, write her up in the 3rd group. Because that one has less. Then...

Sude: There's a 1.73 , a 1.55 .

Ali: There's a 1.55.

Onur: Does the 1.55 go in here (pointing to the 2nd group)? Who?

Sude: Elif's the best one...

Ali: Then write up 1.55 next to her... Write 1.55 here (pointing to the 1st group).

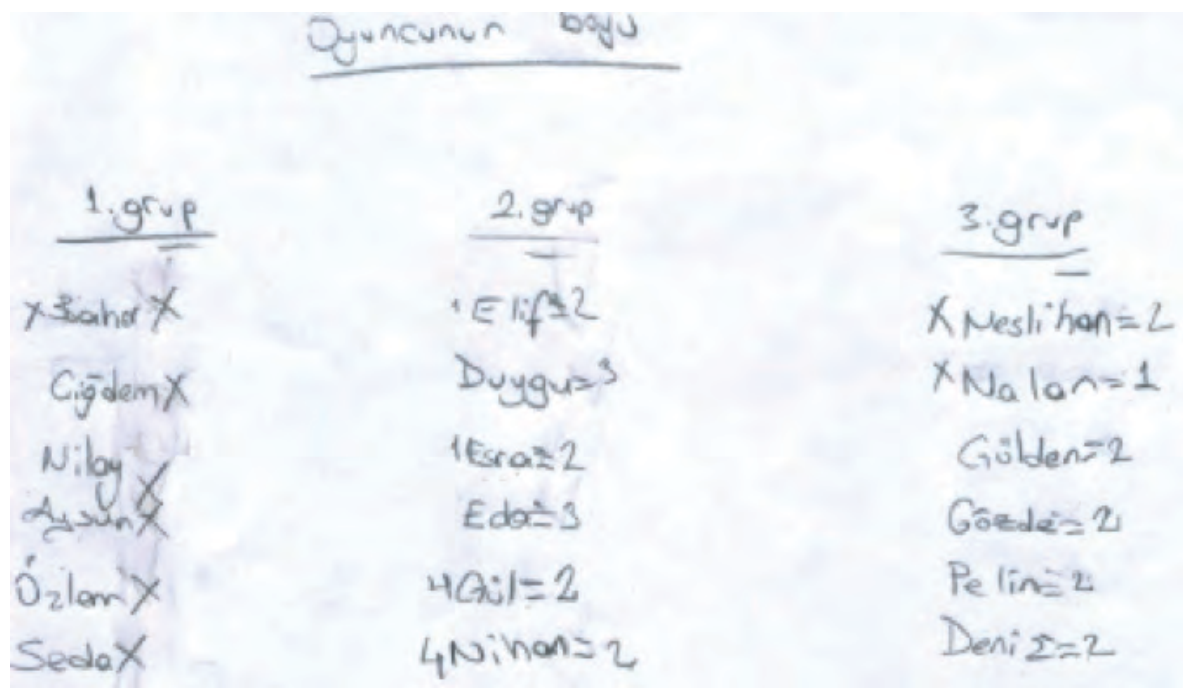

Figure 1.1: The grouping system formed by the group on the basis of the height variable. 
Onur: Who, who?

Ali: Seda. $1 \mathrm{~m} .75 \mathrm{~cm}$. Write up Nihan over there (pointing to the 2 nd group).

In the excerpt above, the data belonging to the three players remaining at the end were first put into order from tallest to shortest and then the players were placed in order into the third, second and first groups. The students worked with a different strategy in the distribution of the first fifteen players but when it was pointed out that the groups were not equal and the third group had short players in it, they used a completely reverse method in the distribution of the remaining three players without making any kind of mathematical calculation. In this, the tallest was put into the third group and the shortest in the first group in an effort to equalize the groups. In the second stage, the data of the vertical leaping variable was considered, starting with the largest value. The students carried out the distribution of the players into groups, putting them into order starting with the one with the highest value down to the one with the lowest, completing their discussion as follows:

Ali: The 1st group. The highest is $69 \mathrm{~cm}$. Neslihan... Now, the ones lower than $69 .$.

Sude: Just a minute, let me look. 66, Gül. 64, Pelin.

Ali: Gül and Pelin.

Sude: There's Gülden.

Ali: Leave her, there's also... We'll look at her again later. Now, let's pick out the ones

that are less than 64 .

Onur: 61

Ali: There's Elif.

Onur: But there's also 64 .

Ali: Let's put her at the end.

Sude: There's a 61 here, there's one here too. Put the 61's in the 3 groups, then.

Ali: Well, did you write up Elif?

Onur: Where?

Ali: Aysun and also Seda.

Sude: What about Ali, or Aysun 58? Eda 61. Don't mix those up.

Ali: Ha! Eda, Eda... Eda.

Ali: When we get to the 3rd group...

Onur: We already wrote up Seda in the 3rd group.
Sude: OK, let's do it again, into the second...

Ali: Now let's look at the ones that are less than 61.

Onur: 60 ?

Ali: We'll look at the ones that are less than 61 .

Sude: ...than 61 .

Ali: Look, there's this Aysun, 58, there are three of these.

Sude: 58. Aysun, Duygu, Deniz. (these are written up in order into the 1st, 2nd and 3rd groups)

In the excerpts above, the students treated the data in the vertical leaping category by using a random comparison method without assigning any particular order to place the players in the different groups (Figure 1.2). In this, the distribution of Gülden (64), Nihan (43), and Nalan (38) into the groups was postponed until the end of the process, and the placement of the remaining three players was discussed in this way:

Ali: We'll look at the ones that are less than 46, $43,38 \ldots$ (reviewing the vertical leaping data)

Then this $43 .$.

Onur: 64, Gülden--where do we put her?

Ali: Well... We'll write up Gülden at the very end. Nihan, write up Nihan. But write up the 43

in... Well, it would be better if we wrote her up in the second group.

Onur: Was it Nihan or who was it? (He adds Nihan to the 2nd group)

Ali: Nihan, Nalan.

Onur: From 1... (He adds Nalan to the 1st group)

Ali: Yes, the 1st group. Then Gülden is 64 . OK, write up Gülden (pointing to the 3rd group)

In the excerpt above, the data belonging to the three players remaining at the end were first put into order from the largest to the smallest value and then the players were placed in order into the third, second, and first groups. The students continued with the strategy they used for the last three players on the basis of the height variable and again did not query whether the groups that were formed were equal or not. In the third stage, the students first determined that the smallest value was the best result in the 40-meter dash, and then, as in the selection of the players on the basis of the first two variables, they used a grouping system, discussing the situation as follows: 


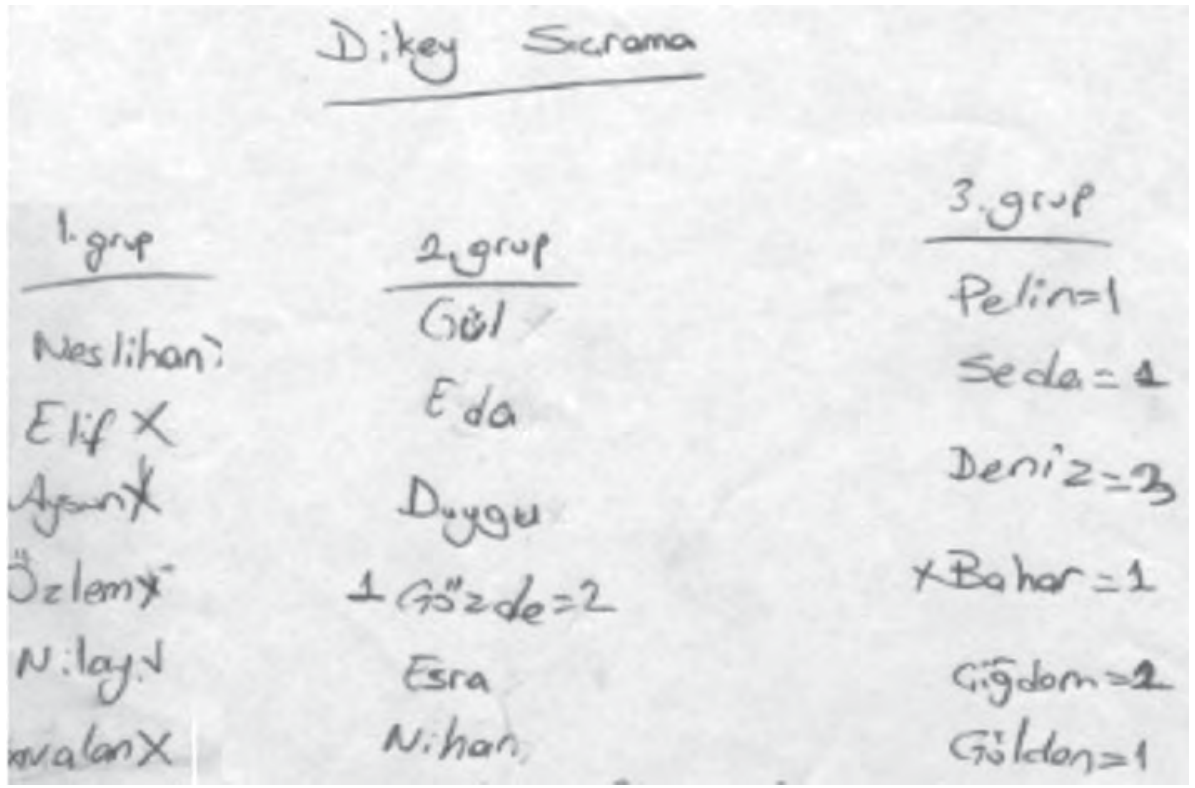

Figure 1.2: The grouping system created by the group for the variable vertical leaping.

Sude: Who are we putting into the 1st group? At least... there's a 5. 5.87. Are there are other 5's?

If there's a 5.98 , before the $5.87 \ldots$

Ali: Write up the 5.87 into the 1st group.

Onur: Who is that? Nalan (adding her to the 1st group for the 40-meter dash)

Ali: Nalan. Write up the 5.98, Pelin.

Onur: Pelin (pointing to the 2nd group)

Ali: There's [someone who's] 6.01 here.

Sude : He's 7. 6.78 means 7.

Onur: Yeah, there's 6.01.

Ali: 6. 6... there's 6.01. Neslihan (pointing to the 3 rd group). Higher than 6.01, there's 6.21.

Bahar (pointing to the 1st group)

Onur: $6.34 \ldots$ there's 6.27 .

Ali: Seda, Eda. (pointing to the 2nd and 3rd groups)...

In the excerpts above, because two players of the same speed could not be found when the players were evaluated, the students were grouped nonsystematically, using random criteria and without leaving any players out as had been the case with the first two variables (Figure 1.3). In other words, there was no consistency in creating a symbolic formula that would be suitable for calculating and finding a mathematical solution from a mathematical model. In the fourth stage with the variable of successful serves, the players were evaluated starting with the largest number of successful serves and were distributed in order into the first, second, and third groups in the following way:

Ali: The number of successful serves... There are 10 in $10.1,2,3$. There are 3.

Onur: Three. From large to small.

Ali: Gülden, Nilay, Çiğdem (placing them in order in the $1^{\text {st }}, 2^{\text {nd }}$, and $3^{\text {rd }}$ groups)

\section{Onur: Çiğdem.}

Ali: Now let's look at the 9's.

Onur: Who's 9?

Onur: Neslihan (placing her in the 1st group)

Ali: Eda (placing her in the 2nd group)

Onur: There's a 9 here.

Sude: Esra...

Onur: Esra. Esra. Esra.

Ali: Esra (putting her in the 3rd group). This 9 is left out. Put that one...

Onur: ...Leave that 9 for now.

In the excerpts above, the students distributed the players on the basis of the variable successful 


\section{0 metredeli kesusu}

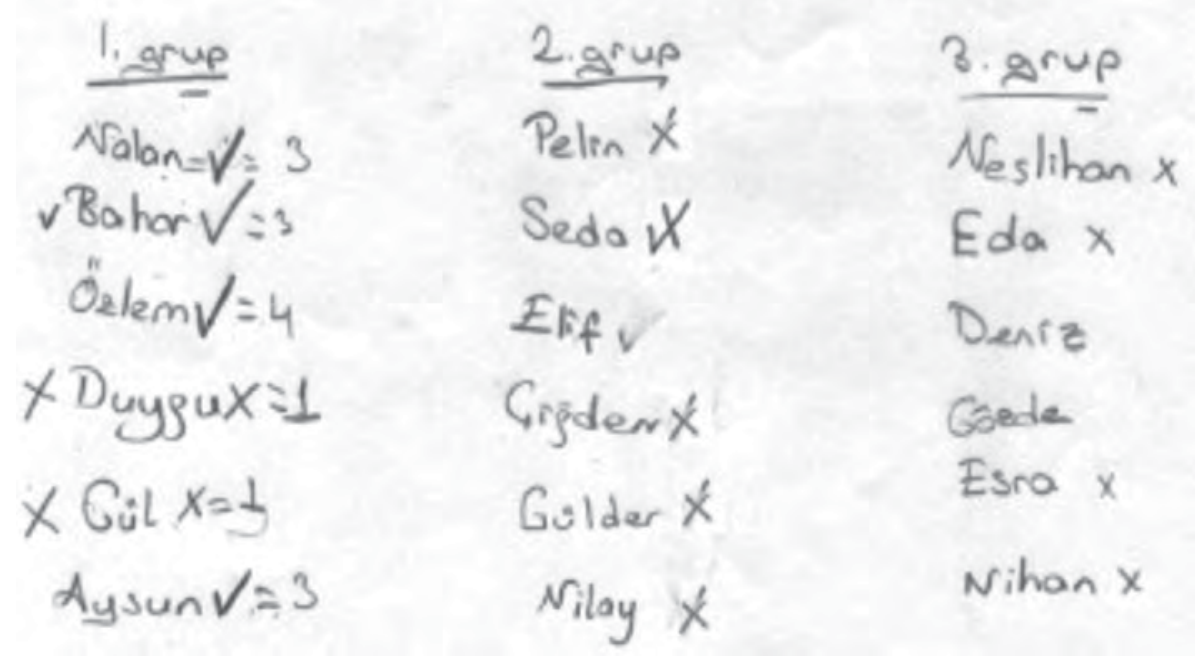

Figure 1.3: The grouping system formed by the group on the basis of the 40-meter dash variable.

serves, using the same strategy they had used for the variables of height and 40-meter dash. The components from the successful serve data were put together from largest to smallest randomly, fitting in a player in each group so that the first fifteen players had been distributed among the groups. During this distribution, Özlem (5), Seda (6) and Gül (9) had been left out so their placement was carried out as follows (Figure1.4):

Onur: Özlem.

Sude: I'm adding this one to the 1st group, right?

Onur: Yup. From now on... (placing Özlem into the 1st group)

Ali: And this 6, 9... Now... the 6, Deniz. Write down Seda, too.

Sude: Into the 3rd group?

Ali: Nope, into the second. Seda (placing her in the 3rd group)

Onur: Seda. Then Gül should be in 3 (pointing to the 3rd group).

In the excerpts above, the students continued the same strategy they had used for the last three players on the basis of the variables height and vertical leaping, not adhering to the appropriate symbolic formula they had adopted at first. After the students set up the groups based on the number of successful serves, they did not question whether the groups had been distributed evenly or not.
In the fifth stage, the model was taken one step further with a comparison after an examination of the first groups to see how many times each player was assigned to this group in terms of the variables of height, vertical leaping, successful serves, and 40-meter dash. The codes the students used in the calculations for the variable of height were discussed as shown below and the results of this discussion are summarized in Table 1.1.

Ali: Now, Bahar, there's 1 here. How many are there over there?

Onur: There's 1 here (pointing to the papers showing the division of the groups).

Ali: There are 3. 1, 2... 3. How many groups were there? Were there 4 ?

Onur: Three.

Sude: Yes, 4.

Ali: From 4 to 3... Now, if we look at Çiğdem...

Sude: Çiğdem...

Ali: There's 1 here.

Sude: There's 1 so I have nothing.

Ali: Let's put an "X" on Çiğdem (marks the name with an X).

Sude: Put an X there and let's take her out.

Ali: Nilay...

Sude: Nilay, I don't have any. 


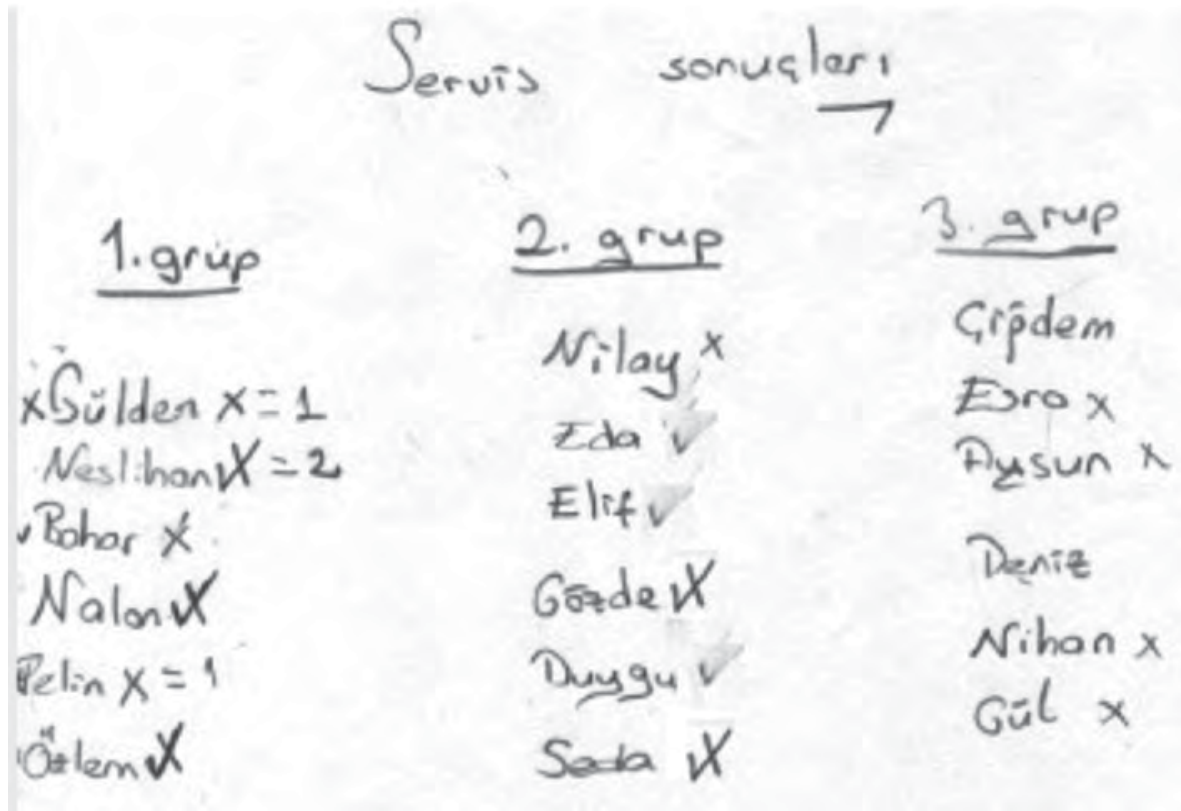

Figure 1.4: The grouping system formed by the group based on the successful serves variable.

Ali: I have 2. Aysun.

Sude: Hmmm. Aysun. There's 1.

Onur: Here's one (pointing to the paper). There's 1.

Ali: There are 3 here. There are 3 here too.

Sude: To the one that are $3 .$.

Ali: Özlem...

Sude: Özlem. There are 1, 2. 4, 4 that one is full.

Ali: Özlem, there are 4. Then this... (crossing it out on the paper).

Sude: Seda...

Ali: Seda, I don't have any. There's 1.

Sude: I don't have any.

Ali: Hmmm, let's put an $\mathrm{X}$ on it (puts an X next to the name).

\begin{tabular}{ccc}
\hline $\begin{array}{l}\text { Table 1.1 } \\
\text { Group 1: Players' } \\
\text { under the Variable of Height }\end{array}$ & \\
\hline Players & Frequency of Placement & Code \\
\hline Bahar & 3 & \\
Çiğdem & 1 & $\mathrm{X}$ \\
Nilay & 2 & $/$ \\
Aysun & 3 & \\
Özlem & 4 & \\
Seda & 1 & $\mathrm{X}$ \\
\hline
\end{tabular}

In the excerpt above, the students tried to determine how many times the players in Group 1 under the height variable were placed in the first group for all the other variables (Table 1.1) in order to develop the model and reach mathematical solutions. At this point, the number of times the players in the first group belonging to the height variable were placed was recorded and an (X) mark was written for only 1 time, a slash (/) was marked for 2 times and when using the coding system, no code was used for 3 or 4 times. In other words, cumulative results were obtained that would enable the interpretation of solutions and then these cumulative results were coded with symbols for abstract reasoning. Similarly, the players in Group 2 under the height variable were reviewed and the number of times they were placed in the second group for all the other variables was calculated. The numbers and the codes used are summarized in Table 1.2.

\begin{tabular}{ccc}
\hline $\begin{array}{l}\text { Table 1.2 } \\
\text { Group 2: Players' Frequency }\end{array}$ & & \\
under the Variable of Height & & \\
\hline Players & Frequency of Placement & Code \\
\hline Elif & 3 & \\
Duygu & 3 & \\
Esra & 2 & \\
Eda & 3 & \\
Gül & 2 & \\
Nihan & 2 &
\end{tabular}


Lastly and similarly, the number of times the players in Group 3 under the height variable were placed in the third group for all the other variables was determined and coded but a systematic method was not used for the same values in any of the coding (Table 1.3.):

\begin{tabular}{|c|c|c|}
\hline \multicolumn{3}{|c|}{$\begin{array}{l}\text { Table 1.3 } \\
\text { Group 3: Players' Frequency of Placement and their Codes } \\
\text { under the Variable of Height }\end{array}$} \\
\hline Players & Frequency of Placement & Code \\
\hline Neslihan & 2 & \\
\hline Nalan & 1 & \\
\hline Gülden & 2 & \\
\hline Gözde & 2 & \\
\hline Pelin & 1 & \\
\hline Deniz & 4 & \\
\hline
\end{tabular}

In all of the above three tables, the cumulative results that would enable the interpretation of the solutions were obtained through mathematical calculations. However, no systematic coding system was used in using the symbols in the three groups and a variable coding approach was employed in all three groups. While in Table 1.2, a slash (/) was used as a code only for Esra, who had a placement frequency of two, in Table 1.3, no coding was used for the values of one, two or four. Also, the students only determined the placement frequency of the players in all three groups under the height variable but did not adopt any kind of strategy to evaluate the players in the groups in terms of the other variables. In the sixth stage, the students focused on the variable of spike results and tried to digitize the qualitative data for this variable as seen below, setting down the steps and codes on the problem sheet as seen in Figure 1.5.

Sude: Put a check on the scores and an $\mathrm{X}$ on the others. X, x, check, check, $\mathrm{x}$ (for Bahar's spike results). Number of attacks, check, return $X$, out of bounds $\mathrm{X}$, dink returned $\mathrm{S}$, number of attacks, check, 2 (for Pelin's spike results). Out of bounds. When the ball is out of bounds, we're already losing points. It should be an X. Then we're not going to count that either. Returned X, returned X, number of attacks, check, in the net X, 1 (for Elif's spike results). Number of attacks, check, number of attacks, check, number of dinks, check, number of attacks, check, returned X, 4 (for Neslihan's spike results). Wait, let me write it down. 2, 2, 1, 4. Out of bounds $\mathrm{X}$, in the net $\mathrm{X}$, returned $\mathrm{X}$, returned $\mathrm{X}$, dink returned $X$, all 0 (for Gülden's spike results).

Onur: Number of attacks 1, number of dinks 1 , number of attacks 1 , returned $\mathrm{X}$, number of attacks, that makes it 1, 4 (for Nihan's spike results).

Sude: Out of bounds X, number of attacks, check, net ball X, net ball X, dink, returned X, 1 (for Özlem's spike results).

Onur: X, check, check, check, check (for Aysun's spike resuts).

Sude: That makes it 4.

Onur: X, X, X, X, X, 0 (for Eda's spike results).

Sude: Check, check, check, X, X, 2 (for Nilay's spike results).

Onur: X, check, X, X, check, 2 (for Duygu's spike results).

Sude: Check, check, check, check, X, 4 (for Nalan's spike results).

Onur: Check, X, X, X, X, 1 (for Gözde's spike results).

Sude: X, X, X, check, X, 1 (for Esra's spike results).

Onur: Check, X, X, check, X, 2 (for Seda's spike results).

Sude: X, check, X, X, X, 1 (for Deniz's spike results).

Onur: Check, X, check, check, check, 4 (for Gül's spike results).

Sude: X, X, check, X, 2 (for Çiğdem's spike results).

In the excerpts above, the students, in exploring the relationship between the components of the variable spike results, created a coding system where they considered the number of attacks and the number of dinks in the system of winning scores, marking these with a check $(\sqrt{ })$; losing points for out of bounds and in the net as well as in situations where the game continued with dinks or returns, they marked with an $(X)$. Later, the checks $(\sqrt{ })$ for each player were added up and the qualitative data was converted into digital data. In other words, the qualitative information was turned into quantitative information, creating cumulative results that enabled the interpretation of the results. However, since the quantitative information obtained on the relationship between the components of the spike results variable was coded the same in the event of losing points or in the event of the continuation of the game, a digitization system was developed here that was a limited representation of the actual fact. In the last stage, as the teams were being formed, the students benefited from the cumulative results 


\begin{tabular}{|c|c|c|c|c|}
\hline \multicolumn{5}{|c|}{ Smac Sonuclan (5 deneme isin) } \\
\hline Plase geri geldi $x$ & Plase sayisi o & Ififcum sayist $V$ & Top filede $x$ & Geril geldi $x$ \\
\hline Ificum sayosi & Geri geldi $x$ & Top disarida $X$ & Plase geri gelali $x$ & Hocum sayasi $\square$ \\
\hline Top disarida $x$ & Geri geldi $x$ & Geri geldi $x$ & Hücum suysi e & Top filede $x$ \\
\hline Hucum sayası & Hotcum sayisi V & Plase sayisi & Höcum sayesi $\mathrm{C}$ & Geri geldi $x$ \\
\hline Top disarida $x$ & Top filede $>$ & Geri geidi X $X$ & Gerigeldi $x$ & Plase geri geldi $x$ \\
\hline HDcum sayisi $~$ & Plase sayist $\Gamma$ & Hticum sayiss & Geri geldi $<$ & Hucum sayss $V^{\prime}$ \\
\hline Top disarida $\times$ & Hucum sayssi & Top filede $x$ & Top filede $x$ & Plase geri geldi X \\
\hline Top filede $x$ & Hücum sayıs V & Hïcum saysis of & Höcum sayisi & Plase sayisi $v$ \\
\hline Top filede $x$ & Top disarida $x$ & Top filede X & Top disanda $x$ & Gicri geldix \\
\hline Plase sayisi $\square$ & Holctim sayisi & Hacum sayza & Top dişanda $X$ & Gien geldi $x$ \\
\hline Plase geri seldix & HAleum sayisi $\leftarrow$ & Geri geldi $x$ & Top disanda $x$ & flōcum sayysı \\
\hline Hücum sayısı $\sqrt{ }$ & Ilticum sayisi o & IIÜcum sayısa V & Plase sayisi of & Top filede $x$ \\
\hline Hōcum sayisi $V$ & Geri geldi $X$ & Top dişaridax & Top filede X & Plase geri geldi \\
\hline Top disarida $x$ & Top filede $X$ & Top filodex & Hocum suryts & Geri geldix \\
\hline Plase sayzst $A$ & Plase geri geldix & Plase geri geldix & 11 itcum saytst $\sqrt{ }$ & Top dişanda $x$ \\
\hline Top dişanda $X$ & Hibcarn sayisi $>$ & Top disarnda $>$ & Plase geri geldi & Top disarida f \\
\hline Plase sayıst & Top filede $X$ & Hociam sayisa $~$ & Hilcum sayisi u & Hocum suyns ic \\
\hline Top filede & Top disanda $\geqslant$ & Hncum sayisi $>$ & Plase geri geldi $/$ & Hücum sayası \\
\hline
\end{tabular}

Figure 1.5 System of coding and digitizing the variable spike results.

and the coding while creating their model and compared these with the spike results in an attempt to set up the first team from out of the equalized teams as below:

Ali: We selected Nalan here, and she's also here 1, 2,3 . There were 3 of Nalan. Bahar 1, 2, 3. Özlem $1,2$.

Sude: Did you select Özlem or Gülden?

Ali: We said we were going to take the ones that are 2 and do it according to these (pointing to the spike results).

Sude: $\mathrm{Oh}$

Ali: Aysun?

Sude: Let me say it, wait.

Ali: 1, 2, 3 (counting the 1st group 40-meter dash, the 1st group player's height and the

1st group's vertical leaping) 3 .

Sude: Nilay?

Ali: Nilay.

Sude: I don't have any (looking at the paper for the 40-meter dash and the successful serves data).

Ali: 1, 2 (counting the player's height in the 1st group and the vertical leaping in the

1st group). Nilay 2.

Onur: Neslihan.

Sude: I have 1 (looking at the 1st group's successful serves data).
Ali: I have one so I now have 2 (looking at the people in the 1st group in vertical leaping).

Sude: Elif?

Ali: I have one too (looking at the people in the 1 st group in vertical leaping).

Sude: I don't have any (looking at the paper for the 40-meter dash and the successful serves data). We were going to put this one in the 2 nd group, weren't we?

Ali: Wait, Nalan, where did we put Nalan? There are 2 here (looking at the paper for the 40 -meter dash and the successful serves data). 1, 2, 3. Now, aren't we selecting one, two, three, four, five, six for the ones in the first group?

Ali: Now, we'll determine these 2's (pointing to the ones above the first group that he created), then we'll look here (pointing to the spike results). Now, how many 2's are there over here, let's calculate (pointing to the people in all the areas).

Onur: So when we finish this and write the letter, are we finished?

Sude: Yes.

Ali: Give me the eraser for a minute and let me erase these (pointing to his own marks in the 2 nd group) - Let's do the 2's and 3's. Let's choose the 2's at most and then we'll look there (pointing to the spike results).

The excerpts above show that the students' selection strategy for the first team was to select the player 
with the highest number of placements in all the groups for all the variables. In this way, the players in the table with the highest number of placements are Nalan (3), Bahar (3), Özlem (4), Aysun (3), Nilay (2) and Neslihan (2), and for this reason, these players comprised the first of the equal teams. Similarly, while they were forming the second team, they used the same strategy they used for the first team. After Duygu (3) and Eda (3) were selected as the first two players for the second team, Esra (2), who had eight serves in her successful serves data and Elif (3), who was 1.78-meters tall, were selected on the basis of height, then Gül (4) and Nihan (4) were added to the team last, making up the second team. Then the remaining six players from the first two teams, Deniz, Gülden, Gözde, Pelin, Seda and Çiğdem, were selected as the players for the third team.

\section{Summary of the Modeling Process Analysis}

In the first stage of the model creation process for the volleyball problem, the middle-school group of 4th-year students, Ali, Onur, and Sude, defined the variable of height as a priority and the first variable used in the first stage of the modeling. The members of the group considered this variable independently and in trying to structure the problem they made the transition of passing from a messy real-life situation to a real-world problem in their modeling process. The students reviewed the components of the height variable and assuming that three teams of equal strength would be formed, they attempted to express the components with an applicable mathematical formula, thus developing a mathematical model.

Later, the group members expanded the variable to include the variables of vertical leaping, 40-meter dash, and successful serves, after which they took each one independently and started to create equal groups within each category. However, when the students were forming the groups for each variable, they did this using different strategies and did not make use of a systematic method. After the group members formed separate groups for the four variables, they defined how many times the players took place in each group, thus creating a model and transitioning into the mathematical modeling stage. With the selection of mathematical concepts and symbols, the students made their mathematical calculations and started producing suitable solutions for the model they had created. The students then tried to use the model to correlate the variables and form associations between them. At this point, the group members were using a coding system that was completely independent and not associated. Moreover, when the students were creating the first model, instead of defining how they were going to evaluate the results obtained from the mathematical solutions, they chose to decide on what kind of strategy they would use after obtaining the mathematical results and started to implement this. In other words, they did not exhibit an approach where they would stick to the model they had created. The students developed a coding system for the qualitative components of the spike results variable. In this system, a digitization system was created that represented the spike results, though in a limited way.

In the next stage, the students obtained solutions from the mathematical model and then used the cumulative results in assigning players to a group. They started placing the player with the highest points in a group. When the cumulative results of the players were equal, they used the method of comparing the figures obtained from finding the solution that they had used for the spike results variable. By doing so, the teams were equalized and this provided a transition from a mathematical solution to real life. At the end of the process, the students did not choose to make any inquiries about whether they had assigned an equal number to each team. They did not review the model they had created and accepted the solution as it was. The students finished their task by writing a letter about the method they had used to solve the problem, which served as a report on the modeling process.

\section{Discussion}

The results of this exercise provide important information about the modeling process that the 4th-year students went through in their modeling activity. The volleyball problem was implemented with a focus group of three 4 th-year middle-school students and their modeling process was examined. All through the activity, the students went through a sequence of cognitive and meta-cognitive thought processes that were not of a linear nature and had to be re-tracked from time to time. The students came up with many different ideas and discussed their various hypotheses until they reached a solution. In other words, the volleyball problem created a powerful learning environment that provided the students with an opportunity to think in depth, set forth, develop, and construct their mathematical concepts. The students shared their own mathematical ideas and experiences to make an association between what the activity taught them and the solution to the problem. 
The results of the grouping in the modeling process showed the difficulties 4 th-year middleschool students have in coping with the process of creating a mathematical model. At the stage where the modeling process transitioned from a messy, real-world situation to a real-world problem, the members of the group took each variable on its own, independent of each other, and tried to find a meaningful solution on the basis of a single variable. At this point, the students experienced the same difficulties as was pointed out by Blum and Leiß (2007) and Sol et al. (2011) in their studies. The students were particularly challenged in interpreting the spike results variable, which had been presented as qualitative data, and could not make a connection by associating all of the variables with each other. In their study of students creating a model, Crouch and Haines (2007) also reported the same difficulty. In the transition from realworld problem to creating a mathematical model, the students in the group could not evaluate all the variables together and were forced to designate a main variable. They then created a model on the basis of assumptions that did not associate the variables with each other. This was consistent with the work of Blum and Leiß (2007) and Schapp, Vos, and Goedhart (2011), who also reported that students did not make use of all of the variables and could not make associations. In addition, similar to the study by Seino (2005), it was seen in the study that making an assumption was an important part of the modeling process. The assumptions made in this study support the findings of Graham (1997), who reported that unordinary hypotheses of students were instrumental in their success of solving the problem and that different hypotheses were based on different models that changed the whole process. As in the studies of Kaiser (2007) and Blum and Leiß (2007), the students had difficulty creating and constructing a suitable model.

In the transition from the mathematical model to the mathematical solution stage, the group members made mathematical calculations based on the models they had created and obtained mathematical results. The students tried to create a model by using all variables, attempting to make a mathematical calculation that would allow them to make associations between the qualitatively stated variables. They were successful in finding mathematical solutions that represented real life, albeit in a limited way. At this stage, the students' approach indicated, as in the study of Blum and Leiß (2007), that they were having difficulty in mathematicizing the modeling process. In the transition of modeling from the mathematical solution to a real-world solution, the group members did not check or inquire whether the teams that had been formed were equal in number. This result is parallel to the studies of Kaiser (2007) and Galbraith and Stilman (2006), where the researchers reported the difficulties students encountered in transferring mathematical solutions to real life; Patel and Ramoni's (1997) mention of students in their study also showed that students do not associate real life problems with models. At the same time, as in Crouch and Haines' (2003) study, the students' approach supports the statement that they were unable to connect the real world to the mathematical world. In the transition from the realworld meaning of the solution to revising the model or accept the solution, the group members accepted the solution as is without reviewing the model. It can be seen from this approach, as in Maaß's (2007) work, that the students were not aware that the model needed to be validated. From the review and adjustment of the model, or validation of the solution, the students completed and reported the modeling process without verifying the adequacy of the model.

To sum up, throughout the modeling process, in developing models suitable to real life situations, the group members experienced difficulties in understanding the problem, discovering the relations between the components of the qualitative variables, associating all of the variables with each other, and hypothesizing. Also, based on their hypotheses, they had trouble creating a suitable model and validating it for the purpose of building an association between real life and mathematics. The reasons for this may have been from the previous thinking habits and experiences with mathematical thinking of the group members, their attitudes towards mathematics, or their creative thinking skills, which are individual characteristics that can all have an impact on the modeling process (Chamberlin, 2004; Ferri, 2004). At the same time, other factors such as students' expectations from the activity and whether or not they found it interesting have been mentioned as also having an effect on the process (Schoenfeld, 1992). In this context, the students' desire to reach a quick solution without spending time understanding or analyzing the problem may also be one of the factors that caused them difficulty (Blum \& Ferri, 2009).

A study of the efforts of students during mathematical modeling activities shows that these activities have a very strong component for 
providing students with communication skills, giving them the opportunity to improve this aspect of themselves. When modeling efforts are implemented in a group activity, students in the group show their ability to ask critical questions; explain, defend, and prove their thoughts; and convince their friends (Zawojewski, Lesh, \& English, 2003). When students express their own mathematical thoughts in words, they need multiple representations of tools to document their own modeling processes (images, figures, tables, graphs, etc.) in order to review their model and test it together. Also, while they are problem-solving, when students express their own thoughts to the others in the group, they are actually engaging in a different activity of reviewing, stage by stage, their own paths of thought. It was observed in the present study that the members of the group exhibited this type of behavior to a small extent. This is made possible by the creation of an effective environment of communication between the members of the group (Maaß, 2007; Schapp et al., 2011).Even though the students in the study had been part of a process-based, student-centered teaching program, the fact that they were unable to transfer this experience to the modeling process, instead acting with a result-focused approach, makes it clear that the new primary school program and its components must be more carefully reviewed (Doruk, 2010). The difficulties students face in the modeling process must be identified and the reasons for deficiencies must be determined so that solutions may be sought to remedy the situation in a system where the vision for the new primary school mathematics program foresees the raising of a new generation of individuals who can form associations between the real world and mathematics, as well as become analytical thinkers who are skilled in problem-solving. Deficiencies may stem from the limited experience of students in and out of the classroom, in working together, participating in activities that require the generation of new ideas, in interpreting, and in sharing. Therefore, it is important that students are provided with learning environments that afford them the experiences that will require them to interpret and work with mathematical situations and share their understanding with peers.

The results of this study are limited to the modeling activity on the thought processes involved in the volleyball problem engaged by a group of three 4th-year middle-school students. New research on mathematical modeling activities should be expanded to include students in preschools, secondary schools, and higher education. Modeling processes should be examined, how modeling knowledge develops and changes over time should be investigated, and how modeling may help to change negative thoughts and opinions about mathematics should be explored, thus extending and enriching the currently scant volume of knowledge on this topic in the national literature. 


\section{References}

Blum, W., \& Ferri, B. R. (2009). Mathematical modeling: Can it be taught and learnt? Journal of Mathematical Modeling and Applications, 1(1), 45-58.

Blum, W., \& Leiß, D. (2007). How do students and teachers deal with modeling problems? In C. R. Haines, P. Galbraith, W. Blum, \& S. Khan (Eds.), Modeling (ICTMA-12): Education, engineering and economics (pp. 222-231). Chichester, UK: Horwood Publishing.

Boaler, J. (2001) Mathematical modelling and new theories of learning. Teaching Mathematics and its Applications, 20(3), 121-128.

Creswell, J. W. (1998). Qualitative inquiry and research design: Choosing among five traditions. Thousand Oaks, CA: Sage.

Chamberlin, M. T. (2004). Design principles for teacher investigations of student work. Mathematics Teacher Education and Development, 6, 61-72.

Crouch, R. M., \& Haines, C. R. (2007). Exemplar models: Expert-novice student behaviours. In C. R. Haines, P. Galbraith, W. Blum, \& S. Khan (Eds.), Mathematical modelling, education, engineering and economics: The ICTMA 12 Study (pp. 101-109). Chichester, UK: Horwood Publishing.

Doruk, B. K. (2010). Matematiği günlük yaşama transfer etmede matematiksel modellemenin etkisi (Doctoral dissertation, Hacettepe University, Ankara, Turkey). Retrieved from https://tez.yok.gov.tr/UlusalTezMerkezi/

English, L. D. (2002). Promoting learning access to powerful mathematics for a knowledge-based era. In D. Edge, \& Y. B. Har (Eds.), Mathematics education for a knowledge-based era (pp. 100-107). Singapore: Association of Mathematics Educators, National Institute of Education.

English, L. D. (2006). Mathematical modeling in the primary school: Children's construction of a consumer guide. Educational Studies in Mathematics, 63(3), 303-323.

English, L. D., \& Watters, J. (2004). Mathematical modeling in the early school years. Mathematics Education Research Journal, 16(3), 59-80.

English, L. D., \& Watters, J. J. (2005). Mathematical modeling in third-grade classrooms. Mathematics Education Research Journal, 16, 59-80.

Ferri, B. R. (2004). Mathematische Denkstile. Ergebnisse einer empirischen Studie. Hildesheim: Franzbecker

Ferri, B. R. (2011). Effective mathematical modelling without blockages- a commentary. In G. Kaiser, W. Blum, R. B. Ferri, \& G. Stillman (Eds.), Trends in teaching and learning of mathematical modelling: The 14. ICMTA study (pp. 181-185). New York, NY: Springer.

Gainsburg, J. (2006). The mathematical modeling of structural engineers. Mathematical Thinking and Learning, 8, 3-36.

Galbraith, P., \& Stillman, G. (2006). A framework for identifying student blockage during transitions in the modelling process. Zentralblatt für Didaktik der Mathematik, 38(2), 143-162.

Graham, T. (1997). The ways in which different students respond to the same mathematical modelling problem. Teaching Mathematics and its Applications, 16, 19-22.

Greer, B. (1997). Modeling reality in mathematics classrooms: The case of word problems. Learning and Instruction, 7(4), 293-307.

Kaiser, G. (2007). Modelling and modelling competencies. In C. R. Haines, P. Galbraith, W. Blum, \& S. Khan (Eds.), Mathematical modelling, education, engineering and economics: The ICTMA 12 Study (pp. 10-119). Chichester, UK: Horwood Publishing.
Kertil, M. (2008). Matematik öğretmen adaylarının problem çözme becerilerinin modelleme sürecinde incelenmesi (Doctoral dissertation, Marmara University, Istanbul, Turkey). Retrieved from https://tez.yok.gov.tr/UlusalTezMerkezi/

Kilpatrick, J. (1992). A history of research in mathematics education. In D. A. Grouws (Ed.), Handbook of research on mathematics teaching and learning (pp. 3-38). New York, NY: Macmillan.

Lesh, R. A., \& Doerr, H. M. (2003). Foundations of a models and modeling perspective on mathematics teaching and learning. In R. A. Lesh \& H. Doerr (Eds.), Beyond constructivism: A models and modeling perspective on mathematics teaching, learning, and problem solving (pp. 3-34). Mahwah, NJ: Lawrence Erlbaum and Associates.

Lesh, R. A., Hoover, M., Hole, B., Kelly, A., \& Post, T. (2000). Principles for developing thought revealing activities for students and teachers. In A. Kelly, \& R. A. Lesh (Eds.), The handbook of research design in mathematics and science education (pp. 591-646). Mahweh, NJ: Erlbaum.

Lesh, R. A., \& Zawojewski, J. S. (2007). Problem solving and modeling. In F. Lester (Ed.), Second handbook of research on mathematics teaching and learning: A project of the National Council of Teachers of Mathematics (pp. 763804). Charlotte, NC: Information Age Publishing.

Maaß, K. (2007). Modelling tasks for low achieving students. First results of an empirical study. In D. PittaPantazi \& G. Philippou (Eds.), CERME 5 - Proceedings of the Fifth Congress of the European Society for Research in Mathematics Education (pp. 2120-2129). Larnaca: University of Cyprus.

Miles, M. B., \& Huberman, M. (1994). Qualitative data analysis: An expanded sourcebook. Thousand Oaks, CA: Sage.

Mousoulides, N. (2007). A modeling perspective in the teaching and learning of mathematical problem solving (Doctoral dissertation, University of Cyprus, Cyprus). Retrieved from http://lekythos.library.ucy.ac.cy/handle/10797/5927

Mousoulides, N., Christou, C., \& Sriraman, B. (2006). From problem solving to modelling- a meta analysis [Online]. Retrieved from http://www.umt.edu/math/reports/srireman/ MousoulidesChristouSriraman.pdf

Patel, V. I., \& Ramoni, M. F. (1997). Cognitive models of directional influence in expert medical reasoning. In P. J. Feltovich, K. M. Ford, \& R. R. Hoffman (Eds.), Expertise in context (pp. 67-99). Menlo Park, CA: AAAI Press/MIT Press.

Schapp, S., Vos, P., \& Goedhart, M. (2011). Students overcoming blockages while building a mathematical model: Exploring a framework. In G. Kaiser, W. Blum, R. B. Ferri, \& G. Stillman (Eds.), Trends in teaching and learning of mathematical modelling: The 14. ICMTA Study (pp. 137-146). New York, NY: Springer.

Schoenfeld, A. H. (1992). Learning to think mathematically: Problem solving, metacognition and sense making in mathematics. In D. Grows (Ed.), Handbook of research on mathematics teaching and learning (pp. 334-370). New York, NY: Macmillan.

Seino, T. (2005). Understanding the role of assumption in mathematical modelling: analysis of lessons with emphasis on the awareness of assumptions [Online]. Retrieved from http://www.merga.net.au/documents/RP762005.pdf

Sol, M., Giménez, J., \& Rosich, N. (2011). Project modelling routes in 12-16-year-old pupils. In G. Kaiser, W. Blum, R. B. Ferri, \& G. Stillman (Eds.), Trends in teaching and learning of mathematical modelling: The 14. ICMTA Study (pp. 231-240). New York, NY: Springer. 
Stillman, G., Galbraith, P., Brown, J., \& Edwards, I. (2007) A framework for success in implementing mathematical modelling in the secondary classroom. Mathematics: Essential Research, Essential Practice, 2, 688-697.

Swetz, F., \& Hartzler, J. S. (1991). Mathematical modeling in the secondary school curriculum. Reston, VA: NCTM.
Zawojevski, S. J., Lesh, R. A., \& English, L. D. (2003). A models and modeling perspective on the role of small group learning activities. In R. A. Lesh \& H. M. Doerr (Eds.), Beyond constructivism: A models and modeling perspective on mathematics problem solving, learning and teaching (pp. 337358). Mahwah, NJ: Lawrence Erlbaum Associates. 